\title{
PROSPECTIVE STUDY TO COMPARE THE FUNCTIONAL AND COSMETIC OUTCOME OF NEUTRAL SAGITTAL ANORECTOPLASTY (NSARP) VERSUS ANTERIOR SAGITTAL ANORECTOPLASTY (ASARP) IN FEMALE INFANTS WITH VESTIBULAR FISTULA
}

\author{
Pramod Kumar Mohantyㄹ, Biswaranjan Mohapatra², Hiranya Kishor Mohanty33, Pradeep Kumar Jena ${ }^{4}$, Gadadhar Sarangi ${ }^{5}$
}

${ }^{1}$ Associate Professor, Department of Paediatric Surgery, SVPPGIP, SCB Medical College, Cuttack, Odisha, India.

${ }^{2}$ Senior Resident, Department of Paediatric Surgery, SVPPGIP, SCB Medical College, Cuttack, Odisha, India.

3 Professor, Department of Paediatric Surgery, SVPPGIP, SCB Medical College, Cuttack, Odisha, India.

${ }^{4}$ Professor, Department of Paediatric Surgery, SVPPGIP, SCB Medical College, Cuttack, Odisha, India.

5Retired Professor and Director, Postgraduate Departments of Paediatrics, Hi-Tech Medical College, Bhubaneswar, Odisha, India.

\section{BACKGROUND} ABSTRACT

Imperforate anus with vestibular fistula is the most common form of anorectal malformation in females. In this anomaly, the development of the sphincteric muscle is usually normal and the fistula or the anus opens below the vaginal orifice in the vestibule near the posterior fourchette surrounded by moist mucous membrane rather than dry skin.

The objectives of study were-

1. To assess the functional and cosmetic results of Neutral Sagittal Anorectoplasty and

2. To compare the outcome of Neutral Sagittal Anorectoplasty with Anterior Sagittal Anorectoplasty.

\section{MATERIALS AND METHODS}

This is a non-randomised controlled trial study carried out in the department of Paediatric Surgery of SVP Post Graduate Institute of Paediatrics, SCB Medical College, Cuttack, Odisha, over a period of two years from Nov 2010 to Oct 2012. Since study duration is short, we had to limit the sample size for convenience. 30 female infants between 3 months to 6 months of age with vestibular fistula, operated in the department were included in the study. Total 30 cases were taken for the study for convenience. This sample size was divided into two groups non-randomly and allocated to either Group A $(n=15)$ or Group B (n=15) with 15 patients each. Group A Patients were subjected to Neutral Sagittal Anorectoplasty (NSARP) \& Group B patients were subjected to Anterior Sagittal Anorectoplasty (ASARP).

\section{RESULTS}

NSARP has given better functional and cosmetic outcome than ASARP. The incision required is small. The perineal body remains untouched and a bridge of skin is left between the anterior part of the neoanus and vestibule. Constipation was more in ASARP group. Cosmetic results are better in NSARP group.

\section{CONCLUSION}

Functional and Cosmetic results are better in NSARP than ASARP.

\section{KEY WORDS}

NSARP (Neutral Sagittal Anorectoplasty), ASARP (Anterior Sagittal Anorectoplasty), AVF (Anovestibular Fistula), PSARP (Posterior Sagittal Anorectoplasty), VF (Vestibular Fistula).

HOW TO CITE THIS ARTICLE: Mohanty PK, Mohapatra B, Mohanty HK, et al. Prospective study to compare the functional and cosmetic outcome of neutral sagittal anorectoplasty (NSARP) versus anterior sagittal anorectoplasty (ASARP) in female infants with vestibular fistula. J. Evolution Med. Dent. Sci. 2018;7(48):5174-5179, DOI: 10.14260/jemds/2018/1148

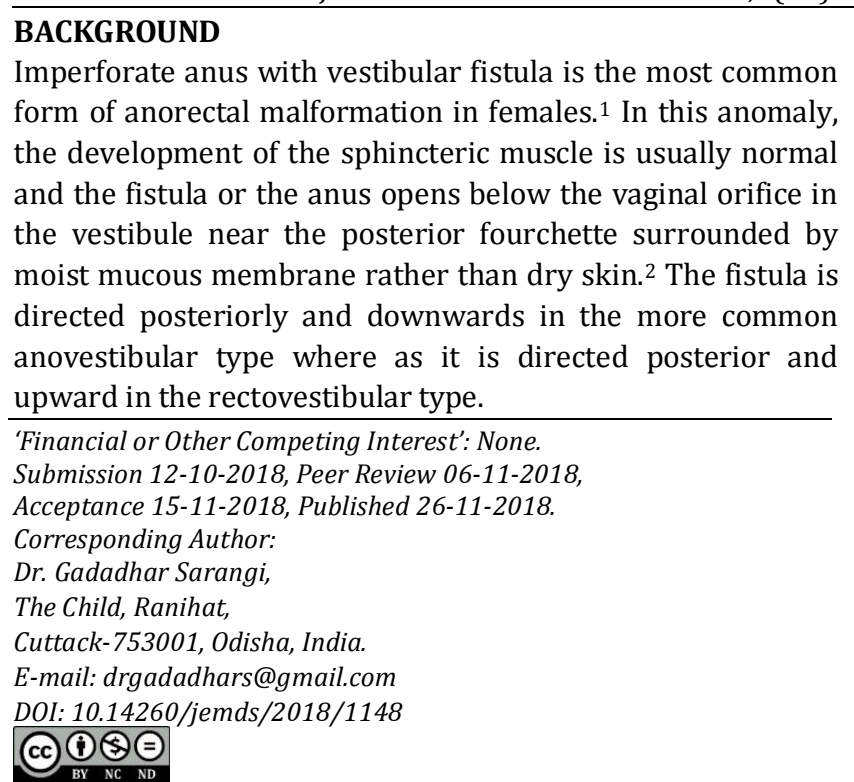

Despite a better understanding of the embryology, anatomy of anorectal malformations and of the physiology of continence, the optimum management of children born with vestibular fistula is still debated. A significant number of these children suffer from constipation, frequent stools, poor perineal cosmesis after surgical management. ${ }^{3}$

The optimal surgical repair should allow easy access to the fistula, minimize the dissection to spare pelvic nerves, guide the rectum through all the muscles of continence, restore a physiological anorectal angle, create good anal opening and take advantage of all existing structures. Most contemporary techniques attempt to achieve these major elements. ${ }^{4}$

Many surgical procedures are described for treatment of this condition, which include cutback, Y-V plasty, perineal anal transposition, sacroperineal repair, PSARP, ASARP, NSARP 5, 6. Better exposure and precise placement of the anal canal within the external sphincter complex have made the posterior and anterior sagittal approaches more popular and 
established for the correction of VF. However, there is still no consensus among paediatric surgeons on what constitutes the best definitive management of children born with a vestibular anus. In the Indian scenario the opinion is very much divided particularly between ASARP and PSARP.

Dave et al 6 described a novel technique, The Neutral Sagittal anorectoplasty or NSARP as an extension of PSARP, which preserves both a perineal skin bridge between the neoanus and the posterior fourchette and the levator muscle. Leaving the perineal skin bridge and the levator muscle intact could be important for the both the aspects of perineal wound-healing and functional outcome. This could be a better option as the anatomy is better delineated in posterior sagittal incision and it also avoids unnecessary cutting of levator and perineal skin bridge as described in conventional PSARP.

In both PSARP and ASARP the perineal body and skin bridge is laid open which is not done in Dave's NSARP with adequate exposure like PSARP. It is also easier to separate the bowel wall from vagina as the separation process taken up from inside the bowel.

Differences in opinion exists regarding the need for a protective colostomy in AVF. Repair under cover of a colostomy is considered the safest option for these cases. ${ }^{7,} 8$ On the other hand, the current trend is to repair these anomalies by one stage correction which avoids the morbidity and mortality associated with colostomy and colostomy closure.9, 10, 11 It also reduces economical and psychological burden on the parents. However, no prospective study has been conducted before to access the functional and cosmetic outcomes of NSARP (Modified

PSARP) in VF. This non-randomized study is undertaken to assess the functional and cosmetic result of NSARP and to compare the outcome with that of ASARP in age matched patients less than 6 months of age i.e breast feeding age when the stool is semi formed.

\section{Aims and Objectives}

1. To assess the functional and cosmetic results of neutral sagittal anorectoplasty (NSARP) as an extension of PSARP in female children with vestibular fistula.

2. To compare the outcome with that of Anterior sagittal anorectoplasty. (ASARP).

\section{MATERIALS AND METHODS}

This is a non-randomised controlled trial study and was approved by the Ethics committee of SCB Medical college, Cuttack. Female neonates and infants with vestibular fistula attending the Paediatric Surgery clinic of SVPPGIP, SCB Medical college, Cuttack, Odisha during Nov 2010 to Oct 2012 were enrolled in the study.

\section{Sample Size}

Total 30 cases were taken for the study for convenience. Thirty age matched female infants with vestibular fistula divided non-randomly into two groups of 15 each were recruited for the study. Consent was obtained from each patient's parent or guardian before enrolling them in the study.

\section{Inclusion Criteria}

1. All female infants with vestibular fistula admitted in the paediatric surgery department operated between 3 to 6 months of age were included in the study.

2. Patients presenting in newborn period who had constipation were treated with repeated fistula dilation and planned for surgery at the minimum age of 3 months.

3. Other group who were not constipated were in regular OPD follow up for planned surgery at minimum 3 months of age.

\section{Exclusion Criteria}

1. Sick babies.

2. Patients with other major congenital anomalies like cardiac, tracheoesophageal anomalies.

3. Anterior placed anus and cloacal anomalies.

4. Other procedure like cutback done elsewhere.

5. Those newborns who did not respond to fistula dilation and require diversion.

6. Patients presenting beyond 6 months of age for first time, were excluded from the study.

\section{Preoperative Assessment}

All the patients were evaluated with a complete medical history, thorough physical examination followed by routine investigations like hemogram, renal function tests, urine routine and microscopy.

Abdominal ultrasonography to determine any renal anomalies, Plain X-ray spine to find any spinal abnormalities and Echocardiogram to rule out cardiac anomalies were done when indicated.

Examination of perineum particularly to find the number of vestibular orifices was done in all cases in good illumination. Probing of the fistula also done in all cases to find out whether the malformation is recto vestibular variety or anovestibular type.

After thorough preoperative workup 30 patients were non-randomly allocated to either group A and B with 15 patients each.

\section{Plan of Surgery}

Group A patients were subjected to NSARP as described by Dave et al $^{6}$ and Group B patients were subjected to ASARP as described by Okada et al.12

\section{Bowel Preparation}

Particular importance was given to preoperative bowel preparation. All cases were prepared by normal saline rectal wash through the fistula for 3 days before the day of surgery. Patients kept nil per oral 12 hours before surgery. A single dose of third generation cephalosporin along with metronidazole was given 12 hours before surgery and continued for 5 days post-operatively.

\section{NSARP Technique}

The skin incision is extended from few cms below the coccyx to the anterior limit of the external sphincter muscle complex.

The perineal body, which lies anterior to the SMC, is not divided. The incision is deepened through the subcutaneous tissues, the parasagittal fibres and the SMC, staying strictly in the midline. In the proximal part of the incision, Levator and 
its lower most fibers was visualized but not incised (Keeping the operation to limited variety of PSARP). In the distal part of the incision after incising the endopelvic fascia the rectum is delineated. Placing a Hegar dilator into the rectum is then opened in its lower most aspect to visualize the VF from inside the rectum. Multiple stay sutures are placed on the superior half of the circumference of the rectum. Inside the opened-up rectum, the inferior most mucosal margin of anterior wall of rectum was elevated by a series of sub mucosal injections of normal saline and a plane is developed and the fistula is dissected off the vagina in the sub mucosal plane initially. The mobilization of the rectum continues cephalad till the vagina is completely separated and the rectum is brought down to the perineal skin level without tension. The VF is closed with interrupted 4-0 vicryl sutures from inside. The pulled through rectum is placed within the SMC and fixed to its re-approximated anterior margin and to its posterior margin extending from the junction of the levator muscle with the SMC until the skin level is reached. The anoplasty is performed in the standard manner. The rest of the skin incision, which extends about $2-3 \mathrm{cms}$ posterior to the neo-anus, is closed by interrupted sutures. The vaginal lumen is specifically examined to rule out any septation or agenesis. Any injury to the posterior wall of vagina repaired with knots inside the vaginal lumen.

\section{ASARP Technique}

The procedure is done with Patient in lithotomy position. A circular incision was made in the mucocutaneous junction at the opening of the fistula and extended posteriorly as a racket shape along the mid line to reach the anal dimple.

Several fine silk traction sutures were inserted around the fistula orifice. Through the incision, the fistula (anorectum) was first dissected little by little from surrounding tissues with meticulous care being taken not to cause damage to the musculature enclosing the rectum. The rectum was separated from the posterior wall of the vagina by sharp dissection. Side by side retrorectal dissection was also done. The length of the rectal tube to be dissected was 4 to $5 \mathrm{~cm}$. Bleeding vessels were controlled by electrocoagulation. The dissected rectal tube was mobilized backward to be placed at the center of the fan-shaped muscles. Anterior ends of the fan shaped muscle fibers were apposed and sutured by interrupted suture with several stitches of 4-0 Vicryl suture beginning from the lower depths upward and outward. The rectum was fixed to the deep external sphincter muscles over its entire circumference by 4-0 interrupted stitches. Sutures were placed between the rectal stump and surrounding skin by about 12-16 stitches of 4-0 Vicryl (Anoplasty).

The neoanus should allow for the initial passage of at least number 10, Hegar dilator in neonates. Then, subcutaneous adipose and connective tissues extending upto the vaginal wall were approximated and sutured with interrupted 4-0 Vicryl. The operation ended with closure of the surgical wound by suturing the perineal skin, with resultant creation of the perineal body. The external sphincter muscle complex is identified by electrical stimulation.

\section{Postoperative Period}

Post-operatively all patients kept on I.V fluids for at least 3 postoperative days to minimize the soiling of wound in either group. Babies were nursed in lateral position and wound exposed on second day. The wound was cleaned with saline and povidone iodine every 12 hourly and after each passage of stool and local antibiotic ointment applied to the perineum. The urinary catheter removed after 5 days and the patients were discharged after $7 / 8$ days.

\section{Follow Up}

Two weeks postoperatively, patients were reviewed to assess the appearance of the perineum, site of the new anus and for calibration and dilatation of the new anus. Thereafter, the patients were followed up every 3 months.

Median follow-up was 12 months (range 3-24 months).

Functional results were assessed by observing the parameters like frequency of stool, constipation, soiling or any incontinence. Cosmetic results for the external genitalia and appearance of the perineum was evaluated by a subjective score ranging from 0 to 3 where 3 is excellent; 2 is fair; 1 is good and 0 is poor or no satisfaction.

All results are expressed as range, mean and percentage. The results for operative, post-operative and follow up period were compared with appropriate statistical test.

\section{Statistical Analysis}

Quantitative data like age at diagnosis, operative age, duration of surgery etc. were described as range and mean of the range. Categorical data were shown as frequencies and percentage. Frequency distribution were shown separately for each patient groups stratified by their functional and cosmetic outcomes. As the sample size was small, percentage was used to compare the functional and cosmetic outcome parameters as well as other quantitative variables. Statistical significance of cosmetic and functional outcome parameters were analysed by Pearson chi square test and Fisher exact test as appropriate. A p-value $<0.05$ was taken as significant.

\section{RESULTS}

During last two years, total number of patients admitted to the paediatric surgery department was 3692, out of which 205 patients had anorectal malformations (ARM). Out of 205 ARM cases number of patients with VF was 44 . Out of $44 \mathrm{VF}$ patients, 14 cases were excluded from our study as per exclusion criteria.

30 patients satisfied the inclusion criteria were categorized non-randomly into two groups of 15 patients each (A and B). In Group A patients, NSARP and in group B patients ASARP was performed.

In group $A$, the age of first presentation ranged between 1 to 60 days with a mean of 17.5 days, while in group B it ranged between 3 to 55 days with a mean age of 20.2 days.

Out of total 30 patients of both groups only 1 patient of NSARP group had rectovestibular fistula. Rest of the 29 patients had anovestibular type. Six patients $(40 \%)$ of group A presenting in newborn period had constipation were treated with repeated dilation of fistula before planning NSARP at minimum 3 months of age. In group B, dilation of fistula was required in 4 patients $(33.33 \%)$ before planning ASARP. 
All patients of both the groups were operated before 6 months, when the stool was semisolid due to breast feeding. The operative age ranged between 120 and 175 days (mean 137.2 days) in group A, while in group B it ranged between 123 and 170 days (mean - 141.1 days).

The operative time ranged between 75 and $110 \mathrm{~min}(85$ minutes) in group A and 75 and 120 min (91 Minutes) in Group B. The age ranges and operative time were comparable between both groups without any statistical significance.

Intraoperative vaginal injury occurred in one patient $(6.66 \%)$ of NSARP group whereas 3 patients (20\%) of ASARP group required repair of vaginal wall while making two walls from one common wall. Similarly, rectal wall thinned out in 2 patients $(13.32 \%)$ of each group requiring reinforcement intraoperatively. Postoperatively 3 patients (20\%) of ASARP group had wound infection with superficial wound gaping. One patient of NSARP group had superficial wound infection. Deep wound infection or major dehiscence was not observed in any patients of both groups. Comparison of intraoperative and early post-operative results in both groups with its statistical significance was done using Fisher Exact Test (Table 1)

\begin{tabular}{|c|c|c|c|}
\hline Variable & $\begin{array}{c}\text { Group A } \\
\mathbf{n = 1 5}\end{array}$ & $\begin{array}{c}\text { Group B } \\
\mathbf{n = 1 5}\end{array}$ & P Value \\
\hline $\begin{array}{c}\text { Intraop Vaginal wall } \\
\text { injury }\end{array}$ & $1(6.66 \%)$ & $3(20 \%)$ & $\mathrm{P}=0.2988$ \\
\hline $\begin{array}{c}\text { Reinforcement of } \\
\text { anterior rectal wall }\end{array}$ & $2(13.32 \%)$ & $2(13.32 \%)$ & $\mathrm{P}=1$ \\
\hline $\begin{array}{c}\text { Superficial wound } \\
\text { Dehiscence }\end{array}$ & $1(6.66 \%)$ & $2(20 \%)$ & $\mathrm{P}=0.5977$ \\
\hline Deep wound gaping & 0 & 0 & $\mathrm{P}=1$ \\
\hline \multicolumn{4}{|c|}{ Table 1. Comparison of Intraoperative and Early } \\
Complications \\
\hline
\end{tabular}

$\mathrm{P}<0.05$ considered significant.

All the patients were called for first follow-up after 2 weeks of discharge from hospital then 3 monthly thereafter. However, after the first visit, 3 patients from group A and 3 patients from group B were lost to follow up.

Out of remaining 12 patients in both group who were on regular follow up. 3 patients from group A and 2 patients from group $B$ were $>2$ years of age. 4 patients from group $A$ and 5 patients of group B were 1-2 years of age and 5 patients of both groups were less than 1 year of age. Till the last follow up no patients had crossed 3 years of age and voluntary bowel activity was not achieved. The functional results were assessed by observing various parameters like frequency of stools, constipation, neoanal stenosis, mucosal prolapse, faecal soiling and incontinence.

Out of 12 patients in NSARP group who were on regular follow-up, 9 patients had good bowel habits with 1-3 bowel movements per day as compared to 6 patients from ASARP group who had 1-3 motions per day. More than 3 stool frequency recorded in 2 patients in NSARP group and 3 patients from ASARP group (Table 2).

\begin{tabular}{|c|c|c|c|c|c|c|}
\hline \multicolumn{2}{|c|}{ Variable } & \multicolumn{2}{c|}{$\begin{array}{c}\text { Group A } \\
\mathbf{n = 1 2}\end{array}$} & \multicolumn{2}{c|}{$\begin{array}{c}\text { Group B } \\
\text { n=12 }\end{array}$} & P-value \\
\hline $\begin{array}{c}\text { Frequent } \\
\text { stools }\end{array}$ & $1-3 / d$ & 9 & $75 \%$ & 6 & $50 \%$ & 0.2059 \\
\cline { 2 - 7 } & $>3 / d$ & 2 & $16.66 \%$ & 3 & $25 \%$ & 0.6152 \\
\hline \multicolumn{2}{|c|}{ Constipation } & 1 & $8.33 \%$ & 3 & $25 \%$ & 0.2950 \\
\hline
\end{tabular}

\begin{tabular}{|c|c|c|c|c|c|}
\hline $\begin{array}{c}\text { Retraction/stenosis } \\
\text { of neoanus }\end{array}$ & 0 & 0 & 1 & $8.33 \%$ & 1 \\
\hline Mucosal prolapsed & 0 & 0 & 1 & $8.33 \%$ & 1 \\
\hline Soiling & 0 & 0 & 0 & 0 & 1 \\
\hline Frank Incontinence & 0 & 0 & 0 & 0 & 1 \\
\hline & Table 2. Functional Results on 3-24 Months Followup \\
\hline
\end{tabular}

$\mathrm{P}<0.05$ considered significant.

Constipation with less than one bowel movements in 3 days with requirement of occasional enema was observed in 1 patient of NSARP group as compared to 3 patients of ASARP group who complained of constipation.

Stenosis of neoanus was observed in 1 patient of ASARP group which was managed conservatively with repeated anal dilation with Hegar's dilator. No patient of NSARP group had stenosis or retraction of neoanus. Mucosal prolapse after 6 months of follow up was noticed in 1 patient of ASARP group. No patients from NSARP group developed this complication (Table 2).

No patients of both NSARP and ASARP group had soiling or frank incontinence of stool during follow up.

The cosmetic results of the perineum were assessed at 6 months postoperatively in all cases with arbitrary score ranging from 3 to 0 . Appearance of external genitalia and appearance of the perineum was evaluated by a subjective score ranging from 0 to 3 where 3 is excellent; 2 is fair; 1 is good; and 0 is poor or no satisfaction.

In NSARP group, 6 patients had excellent cosmetic score of 3 with parents fully satisfied as compared to 4 patients in ASARP group who recorded a score of 3. A cosmetic score of 1 and 2 recorded in 6 patients of NSARP group while 7 patients of ASARP group had a cosmetic score of 1 and 2. One patient of ASARP who developed mucosal prolapse score 0 with parents not satisfied at all with the appearance of perineum at 1 year of age where as no patients of NSARP group had score 0 till the last follow up.

\section{DISCUSSION}

Many surgical procedures are used for treatment of anovestibular and rectovestibular fistulae, which include cut back, perineal anal transposition, Y-V plasty, posterior anal transfer, colostomy followed by PSARP, ASARP, NSARP.5,6

Because of better delineation of anatomy and precise placement of rectum within the SMC, both the anterior and posterior sagittal approaches are commonly used to restore normal anatomy in VF.

The ASARP technique is an established technique for this anomaly with very good results. ASARP technique is claimed to be superior to Pena's PSARP technique in terms of the amount of dissection required. Supine position in ASARP also is advantageous for anaesthesia. Many authors claim that the separation of rectum from vagina is directly under vision in ASARP.8,12,13

NSARP technique as an extension of PSARP described by Dave has the advantages of posterior sagittal incision with better delineation of anatomy without cutting the levator muscle and it also preserved the perineal skin. Dave ${ }^{6}$ claimed that the NSARP technique is technically less demanding and the functional results achievable by NSARP match those of PSARP and ASARP. However not many studies were described in the literature after Dave's description of this procedure and also no prospective randomized study to 
compare the functional outcomes of these techniques has been conducted till date.

The present study designed this non-randomized controlled trial study to compare the functional and cosmetic results of NSARP and ASARP in 30 female infants with VF operated in breast feeding age (Between 3-6 months) in single stage when the stool is semisolid.

This study has 15 patients in each group of NSARP and ASARP. The age at diagnosis, age at operation were comparable between the two groups.

The median operative age is 137.2 days in NSARP group where as it is 141.1 days in ASARP group, most cases in either group were operated in the first 6 months of life.

The mean operative time was less for NSARP as compared to ASARP (85 mins VS 91 mins). However, the operative time is comparable with other studies for ASARP. 12,14,15

In addition, in this study the feasibility of one stage repair of VFs whether NSARP or ASARP is confirmed as documented in former reports. ${ }^{11,16,12}$

Operative vaginal wall opening was less frequent in NSARP group. It occurred once in group $A$ and 3 times in group B (6.66\% in gr A vs $20 \%$ in gr B, P value 0.29$)$. The incidence of intra-operative vaginal injury in ASARP is comparable to Shaheta et al who reported $16 \%, 5,14$ while others reported lesser incidence. ${ }^{11,17}$

The reinforcement of the anterior rectal wall after it was thinned out during separation from vaginal was required in two cases each of ASARP group and NSARP group which was comparable to other studies. ${ }^{17,18}$

Post-operative superficial wound infection was reported once in group A and 3 time in group B with $\mathrm{P}$ value of 0.11 and all treated conservatively without seuqelae. Zamir et al ${ }^{14}$ reported infection rate of $7 \%$ in his series and $16 \%$ in Aziz et al ${ }^{15}$ following ASARP technique. Shaheta et al ${ }^{5}$ reported a wound infection rate of $10 \%$ in ASARP group and $20 \%$ PSARP group. Kaddah ${ }^{13}$ reported infection rate of $24 \%$ in his PSARP series. No complete wound dehiscence was seen in this series as all infections were superficial.

Despite that the same pre and peri-operative protocols were implemented to both groups of patients, NSARP group has lower infection rate than ASARP group. This result could be attributed to the non-cutting of posterior muscles and also preservation of an intact perineal skin bridge between the neo-anus and posterior fourchette. The wound posterior to the neo-anus healed satisfactorily in all the patients who had undergone NSARP. The wound infection rate in NSARP is comparable to the Dave's series of 12 NSARP cases. ${ }^{6}$

The total followup period ranged between 03 and 24 months. Six patients, 3 from each group were lost to follow up after the 2 nd post-operative visit. Rest 12 patients from each group were on regular follow up. Early functional assessment was carried out for 12 cases from both groups who passed the 3 months post-operative time and strict to the follow - up visits. As all the patients were less than 3 years of age during the study and have not achieved voluntary bowel control, Parameters like frequency of stool, constipation, soiling, mucosal prolapse and neoanal stenosis were used to compare the functional results of both groups.

During the time of functional assessment, 9 cases in NSARP group and 6 patients in ASARP group out of 12 cases had normal bowel movements of once or twice a day. Two cases of NSARP and 3 patients of ASARP group had frequent stools which improved from several times daily in first 3 months to 3-5 times per day till the last follow up.

Constipation was reported in 2 patients in NSARP group and 5 patients in the ASARP group in first 3 months of followup. Till the last follow up these patients managed with dietary modification and occasional enema, 1 (8.33\%) patient of NSARP group still having the problem whereas 3 (25\%) patients of ASARP group still require occasional enema. The lower incidence of constipation in NSARP group may be due to the technical modification in which the distal most part of the fistula is excluded, and full thickness wall of rectum was anastomosed with the skin. This is supported by the histological findings of aberrance muscle fibers and excessive fibrous tissue in terminal part of the fistula as reported in Holschneider et al.19

During 6 months follow up, one patient developed mucosal prolapse and one patient had neoanal stenosis, both from ASARP group. The patient with neoanal stenosis was managed conservatively with regular dilation and improved. The case with mucosal prolapse was also on conservative management. However, these complications were not observed in any patient of NSARP group.

No patient had soling or frank incontinence of stool till the last follow up. In the current study, prospective evaluation of functional outcome in VF repair shows better results in NSARP group when compared to ASARP group despite no statistical significance being found.

To evaluate cosmetic results arbitrary score from 0 to 3 was used. The NSARP group again had better cosmetic results than ASARP group. The perineum looks near normal in 6 patients of NSARP group with parents fully satisfied as compared to 4 patients of ASARP group. One patient of ASARP group who had mucosal prolapse had poor cosmetic results with parents not satisfied at all with the cosmetic results. No patient of NSARP group had a zero or poor cosmetic score. The result of the current study is better than the previous reports. ${ }^{5,14}$ However statistical analysis did not show any significance between the two groups.

The overall improved cosmetic and functional outcome could be attributed to the fact that NSARP technique allows a safe dissection and preservation of levator muscle as well as the peineal skin bridge. 6

Former literature either compared different group of ARMs in girls11,16,20,15 or were only retrospective studies 21,22 or compared the conventional PSARP with ASARP. ${ }^{5}$ This is the first non-randomized controlled trial study designed to compare the functional outcomes of NSARP and ASARP in the treatment of girls with VFs. The results of this study show that NSARP is a better technique for treatment of vestibular fistula in girls. Perineal cosmetic results were superior to ASARP. Excellent continence was achieved in most of the assed cases following ASARP or NSARP techniques.

Despite the observations that functional results at early and medium follow-up period give higher scores in NSARP group as compared to ASARP group, no statistical significance could be established. Larger numbers from both groups of patients and longer follow up periods are needed to validate the current results.

\section{Procedural Difference between PSARP and NSARP}

The basic differences between the two is, in the NSARP approach, the incision is much smaller and extends few $\mathrm{cms}$ 
from coccyx and stops exactly at the anterior limit of proposed neoanus or SMC. Perineal body remains untouched in NSARP and the dissection and closure of the VF is done entirely from within the opened bowel while in limited PSARP approach, the incision extends upto the fourchette and encircles the fistula in a racket shaped incision.

\section{Limitations}

Since the study duration was short, we had to limit the sample size for convenience.

\section{CONCLUSION}

Probably this is the first non-randomized controlled trial study designed to compare the functional outcomes of ASARP and NSARP in the treatment of female children with vestibular fistula. The results of this study show that NSARP as an extension to PSARP is a better technique for treatment of this anomaly. It has all the advantages of PSARP with a smaller incision that leaves the perineal body and skin bridge intact.

Perineal cosmetic results and parental satisfaction regarding perineal cosmesis were superior to ASARP. Excellent continence was achieved in most of the assessed cases following NSARP or ASARP techniques. Though functional results are better in NSARP than that of ASARP, no statistical significance could be attached to it. Larger numbers of patient from both groups particularly with NSARP and longer follow-up periods are needed to validate the current results.

\section{REFERENCES}

[1] Spouge D, Baird PA. Imperforate anus in 700, 000 consecutive liveborn infants. Am J Med Genet Suppl 1986;2:151-61.

[2] Freeman NV. Anorectal malformations. In: Freeman NV, Burge DM, Griffiths M, et al. eds. Surgery of the newborn. Edinburgh: Churchill Livingstone 1994: p. 171-99.

[3] Smith ED. The bath water needs changing, but don't throw out the baby: an overview of anorectal anomalies. J Pediatr Surg 1987;22(4):335-48.

[4] Yazbeck S, Luks FI, St-Vil D. Anterior perineal approach and three-flap anoplasty for imperforate anus: optimal reconstruction with minimal destruction. J Pediatr Surg 1992;27(2):190-5.

[5] Shehata SMK. Prospective long-term functional and cosmetic results of ASARP versus PSARP in treatment of intermediate anorectal malformations in girls. Pediatr Surg Int 2009;25(10):863-8.

[6] Dave S, Shi ECP. Perineal skin-bridge and levator muscle preservation in neutral sagittal anorectoplasty (NSARP) for vestibular fistula. Pediatr Surg Int 2005;21(9):711-4.

[7] Heinen FL. The surgical treatment of low anal defects and vestibular fistulas. Semin Pediatr Surg 1997;6(4):204-16.
[8] Kulshrestha S, Kulshrestha M, Sing B, et al. Anterior sagittal anorectoplasty for anovestibular fistula. Peditr Surg Int 2007;23(12):1191-7.

[9] Demirbilek S, Atayurt HF. Anal transposition without colostomy: functional results and complications. Pediatr Surg Int 1999;15(3-4):221-3.

[10] Adeniran JO. One stage correction of imperforate anus and recto vestibular fistula in girls: preliminary results. J Pediatr Surg 2002;37(6):E16.

[11] Menon P, Rao KLN. Primary anorectoplasty in females with common anorectal malformations without colostomy. J Pediatr Surg 2007;42(6):1103-6.

[12] Okada A, Kamata S, Imura K, eta al. Anterior sagittal anorectoplasty for rectovestibular and ano-vestibular fistula. J Pediatr Surg 1992;27(1):85-9.

[13] Kaddah SN. One stage repair of intermediate and high anorectal malformations in newborn. Ann Peditr Surg 2007;3:144-9.

[14] Zamir N, Mirza FM, Akhtar J, et al. Anterior sagittal approach for anorectal malformation in female children: early results. J Coll Physicians Surg Pak 2008;18(12):763-7.

[15] Aziz MA, Banu T, Prasad R, et al. Primary anterior sagittal anorectoplasty for rectovestibular fistula. Asian J Surg 2006;29(1):22-4.

[16] Wakhlu A, Pandey A, Prasad A, et al. Anterior sagittal anorectoplasty for anorectal malformations and perineal trauma in the female child. J Pediatr Surg 1996;31(9):1236-40.

[17] Pena A. Posterior sagittal anorectoplasty: results in the management of 332 cases of anorectal malformations. Pediatr Surg Int 1988;3(2-3):94-104.

[18] Levitt MA, Pena A. Operative management of anomalies in females. In: Holschneider AM, Huston JM, eds. Anorectal malformations in children: embryology, diagnosis, surgical treatment, follow-up. $1^{\text {st }}$ edn. Berlin: Springer 2006: p. 303-7.

[19] Holschneider AM, Koebke J, Meier-Ruge W, et al. Pathophysiology of chronic constipation in anorectal malformations. Long-term results and preliminary anatomical investigations. Eur J Pediatr Surg 2001;11(5):305-10.

[20] Pena A, Migotto-Krieger M, Levitt MA. Colostomy in anorectal malformations: a procedure with serious but preventable complications. J Pediatr Surg 2006;41(4):748-56.

[21] Javid PJ, Barnhart DC, Hirschi RB, et al. Immediate and long-term results of surgical management of low imperforate anus in girls. J Pediatr Surg 1998;33(2):198-203.

[22] Kumar B, Kandpal DK, Sharma SB, et al. Single stage repair of vestibular and perineal fistulae without colostomy. J Pediatr Surg 2008;43(10):1848-52. 